\title{
Understanding Word Of Mouth (WOM) Communication: A Case Study of Banking Sector in India
}

\author{
Dr. Jaskaran Singh Dhillon, Director \\ Swift Institute of Management and Computer Science, Swift Technical Campus Rajpura-Patiala (Punjab)
}

\begin{abstract}
Financial service providers have long placed considerable faith in positive word of mouth communication as a means of attracting new customers and a variety of studies of customer choice of bank highlight the significance of personal recommendation. Given that financial services tend to be characterised by a predominance of experience and credence qualities, word of mouth communication is particularly valuable, providing the potential consumer with vicarious experience of the service under consideration. The impact of word of mouth is probably at its strongest when it originates from social contacts because of their greater perceived reliability. By its very nature, this form of communication is outside the formal control of an organisation and yet its impact is such that the ability to influence or encourage word of mouth could be a powerful marketing tool. This paper provides an exploratory analysis of the importance of word of mouth and the factors which influence its role within an organisation's marketing strategy, with particular reference to customer referral campaigns. Empirical evidence is collected from the (rapidly changing and liberalising) financial services sector in India.
\end{abstract}

Keywords: Communication, Banking, Consumer Behaviour, Word of Mouth (WOM), Strategy

\section{Introduction}

Many marketers would consider positive word-of-mouth (WOM) as perhaps one of the oldest forms of marketing communication, whether from the vendor (or representative),from experts or from social acquaintances including friends and family. In many circumstances, it may also be one of the most powerful and particularly so if the provider of WOM is someone known and trusted (family, social acquaintances). Like any form of communication, the value of WOM will vary across product, market and organisational contexts, but might be expected to be most powerful in the presence of products which have predominance of experience and credence qualities and for products for which the perceived risk associated with purchase is high. Not surprisingly then, WOM has received particular attention from a services perspective, but the research to date has been dominated by a customer focus. The majority of researchers have focused either on why some individuals provide WOM and why and how others use it. Because WOM is formally outside the control of the product provider, there have been few attempts to examine the role of WOM (whether from customers or another group) within marketing strategies. Building on and extending the work of Helm and Schlei (2008), this paper aims to explore the relationship between product, market and organisational characteristics and the role of WOM within an organisation's marketing strategy. This examination includes, but is not restricted to, consumer referral campaigns. Furthermore, while recognising the potential importance of informal WOM which might originate from present or past employees the current study focuses only on customer generated WOM.

Given their specific characteristics, financial services were selected as the context for empirical work and data were collected from India. The Indian financial services sector has undergone a process of liberalisation and is characterised by a mix of public and private organisations, indigenous firms and overseas entrants. Like many Western financial services sectors, it is highly competitive but the developing country environment and the growth potential within the sector provide an interesting context in which to study WOM.

The paper begins with a brief overview of WOM, focusing primarily on its positive dimensions. From this review, it is apparent that the organisational perspective on WOM has received comparatively little attention. Accordingly, the next section highlights key issues from the organisational perspective and proposes a research agenda. This research agenda places particular emphasis on the relationships between the role of WOM in marketing strategy and the product-market context. Subsequent sections deal with data collection and analysis while the final section provides a summary and conclusions.

WOM communication: an overview the term WOM is used to describe verbal communications (either positive or negative) between groups such as the product provider, independent experts, family and friends and the actual or potential consumer (Helm and Schlei, 2008). Although all three groups may engage in WOM, most research has tended to focus on WOM between actual and potential customers, usually from largely family or social sources. Thus, Cox (1967) refers to WOM advertising quite simply, as nothing more than a conversation about products while Arndt(1967) formally defines WOM advertising as, oral, person-to-person communication between a perceived non-commercial communicator and a receiver concerning a brand, a product or a service 
offered for sale "and goes on to describe informal conversation as probably the oldest mechanism by which opinions on products and brands are developed, expressed and spread.

The value of WOM arises as a consequence of its impact on actual and potential buyers. Positive comments from satisfied customers can increase purchases (from that customer and others), while negative comments from dissatisfied customers can decrease purchases (from that customer and others). Thus, for example, Katz and Lazarfeld (1955) found personal influence to be seven times more effective than magazine or newspaper advertising, at persuading housewives to switch brands of household products.

Similarly, Beal and Rogers (1957), found interpersonal sources to be most effective in persuading housewives to try new fabrics and change supermarkets respectively. More recently, a study conducted by the White House Office of Consumer Affairs (Walker, 2005) found that at least 90 per cent of dissatisfied customers do not intend to repertories an unsatisfactory company.

Moreover, each of these unsatisfied customers are expected to express their disappointment to a minimum of nine other individuals, and around 13 per cent will communicate their dissatisfaction with accompany to more than 20 individuals.

The potential impact of WOM and its value to an organisation is thus considerable, although as an informal channel, the opportunities for organisations to manage WOM may be more difficult to identify. Certainly, the bulk of the research that has been undertaken in relation to WOM communication has tended to focus attention on the consumer as a user of WOM or the consumer as a provider of WOM.

In considering the consumer as a user of WOM, the dominant explanation focuses on the role of WOM as a riskreliever or as a risk reduction strategy (Derbaix, 1983; Kaplanet al., 1974; Roselius, 1971). Its importance arises from its ability to create a more informed choice, such that when consumers receive WOM regarding a particular product or service, they can benefit from reduced perceived risk by either decreasing the probability that the purchase will fail, or by reducing the severity of real/imagined loss suffered if the purchase does fail or equally by shifting from one type of perceived loss to another for which there is greater tolerance. Roselius (1971) found that WOM evoked a neutral or slightly favourable response in relieving all types of risk apart from physical risk[1]. More risk averse consumers found WOM to be a very useful strategy in reducing most types of risk, and particular consumers were found to rate WOM particularly highly.

Cox (1967) in a detailed qualitative study of risk handling in consumer behaviour, found that asking family and friends for advice played a crucial role in assisting consumers to make an informed purchase decision. Cunningham (1967), found that for two out of three products, high risk perceivers were more likely than low risk perceivers to have been involved in product related conversations during the last six months.

Consideration of consumers' motives for engaging in WOM has tended to highlight the importance of customer satisfaction and related outcomes as a determinant of positive WOM. There is widespread evidence of the relationship between satisfaction and the desire to recommend (Hartline and Jones, 1996; Parasuraman et al., 1988; Selnes, 2003, Shemwell et al., 1998; SoÈderlund, 1998, Yi, 2009). Equally there are arguments to associate dissatisfaction with negative WOM. Certainly dissatisfaction has been widely identified as an antecedent to complaining behaviour but in instances where consumers feel unwilling or unable to complain (perhaps because of a reluctance to challenge professional judgement (Singh, 1990)), dissatisfaction can serve as an antecedent to negative WOM. The form of the relationship between satisfaction and WOM is open to debate and there is evidence to suggest that the relationship may be asymmetric and thus different at different levels of satisfaction.

There are arguments to favour a negative asymmetry where consumers with bad experiences tell more people than those with good experiences (Hart et al., 2007). Equally, there is also evidence to suggest that positive events produce a stronger response under certain conditions (a positive asymmetry) (Holmes and Lett, 2007).

Customer loyalty also plays an important role as an antecedent in WOM communication. Gremler and Brown (1996) argue that loyal customers are a prerequisite for positive WOM. A relationship that is also supported by Reichheld and Sasser (1990), who cite a study by General Electric which found that recommendations from friends and acquaintances carry twice the impact of paid advertising when consumers make purchasing decisions. In addition, Gremler and Brown (1996) propose that customers who provide other consumers with positive WOM, about a service or service provider, are more likely to become loyal customers themselves, thus implying that WOM may have benefits in terms of retention as well as acquisition. The role of WOM communication is considered to be particularly significant in a service context because the predominance of experience and credence qualities in services suggests that consumers experience a higher degree of perceived risk in making a purchase decision. In a review of the services literature, Gabbott and Hogg (2004) discern that the need for experience-related information on services prompts a reliance on WOM sources (Zeithaml, 1981) which is consistent with the contention that WOM sources are pivotal in relation to services (Myers and Robertson, 1972; Eiglier and Langeard, 1977; Urbany and Weilbacker, 1987). Likewise, Mitchell and Greatorex (1993) find that asking the advice of family and friends is important for most services and evidence furnished by Murray (1991) confirms that service consumers prefer the opinions and experiences of other comparable 
individuals in making service purchase decisions. Bharadwaj et al. (2003) argue that when buyers cannot easily evaluate the qualities and value of the service or capabilities of the service provider, then reputation, stimulated predominantly through positive WOM, may serve as an important proxy for more detailed evaluation. They continue by stating that those services which are highly intangible, and therefore high in experience and credence qualities, will find reputation an important potential competitive advantage.

While we have valuable insights into why consumers use WOM (risk reduction) and why they might engage in WOM, (satisfaction, loyalty), there is rather less known about the importance that firms attach to WOM, its role in marketing strategies and the extent to which they attempt to manage this form of communication.

Given that WOM is a highly informal style of communication, managing the process is likely

to prove difficult simply because the communicator is not within an organisation's direct sphere of influence. Furthermore, given the potential for WOM to reflect on the integrity of the deliverer, the scope for organisations to be able to persuade unhappy customers to recommend a service is limited.

In that sense, and as the research findings above would tend to imply, delivering customer satisfaction is probably the most obvious and necessary way to manage WOM. However, not all satisfied customers will engage in positive WOM leaving a role for the organisation to consider how it may attempt to convert satisfied customers into advocates. Several options are available. For example, Katz and Lazarsfeld (1955) highlight the role of opinion leaders as sources of WOM suggesting that proactive marketing targeted at such groups is one way of encouraging WOM. Thus, for example, Javalgi (1995) reports a 7 per cent increase in referrals as a consequence of a marketing campaign targeted specifically at referring physicians (as opinion leaders).

Customer referral campaigns (CRCs) are one of the most direct forms of managing WOM and promoting customer acquisition. These are campaigns based on providing an incentive to actual customers for referring and attracting new customers to the organisation. In the UK, American Express and the Institute of Directors both offer gifts as incentives to "members" who introduce new "members". A similar approach is used in India by Citibank, ANZ/Grindlays and American Express who seek to "incentivise" existing card holders to recommend the card to a friend. In a slightly more subtle approach, Cellnet, in the UK, advertises free calls to "members" and encourages them to make a call and tell a friend. Helm and Schlei (2008), in a focused study of the benefits of CRCs, found that 52.8 per cent of their respondents categorised CRCs as especially important in acquiring new customers, and that CRCs were implemented predominantly through targeted mail (53.3 per cent). They state that CRCs are an effective method for directly communicating with prospective customers, finding that physical goods are the main incentive for referring customers (81.8 per cent). Furthermore, 33 percent of respondents expected to reach a break-even point earlier than with other forms of customer acquisition and 80 per cent of respondents felt that opinion leaders could be targeted through CRCs, though the adverse effects of negative referrals were also considered a possibility by 37.5 per cent of participants. By drawing on such evaluations by managers, the authors provide possible criteria for designing effective measures of CRCs, relating to both customer and product related factors. Customer related factors, such as the accessibility of customers through direct marketing and their attitudes towards the incentive are identified. Product related factors evaluating the suitability of a product for a CRC include the product's stage in the product life cycle (where later stage products will have more experienced customers who can recommend). However, they highlight that a variety of other factors, such as the timing of a CRC, market structure and competitive behaviour also impact upon the success of a CRC.

To conclude, Haywood (2009) provides an encompassing 13-point plan, for the management of WOM directly through acquisition and indirectly through retention. First, he stresses the need to listen actively and question effectively, by interacting with customers on a personal level. Once relationships with customers have been built and the issues regarding WOM identified, then managers can implement the appropriate actions. Haywood stresses the need to be customer orientated, by having a strong company-wide commitment to service and quality that generates the positive experiences that customers value and resolves the negative ones that they do not.

He also emphasises the need to deliver on promises, for WOM to be fully leveraged and also the need to capitalise on WOM after a customer has left the establishment, through methods such as mementos to stimulate WOM. Targeting of opinion leaders and generation of interest through advertisements are suggestions that have already been touched on.

Working with suppliers who can engage in WOM with other client companies can promote positive and limit negative WOM. Joint advertising campaigns is one method competitors can use to work together for mutual benefit to serve larger clients or refer excess business. Such co-operation is said to engender positive feelings and WOM.

By helping potential customers seek information, via methods such as free-call numbers and coupons, positive WOM may be stimulated in customers who are pleased by the business's interest in them. Such perceptions require employees and managers to be effective communicators. However, not all employees are loyal, which requires firms to limit any damaging remarks or leaked information that could affect a firm's image and strategy. 
In the same way that internal marketing is important in generating a marketing orientation, there may also be a need for the management of internal WOM from staff. Finally, Haywood stresses the need to find out what competitors and their customers are saying, by tapping into managers' information networks, attending conferences or by creating research and development programs.

Organisational Perceptions and Management of WOM: From the review of the literature in the previous section it is apparent that there is little systematic evidence on the importance and management of WOM from an organisational perspective. The study by Haywood (2009), although providing valuable insights across a broad range of issues, is largely prescriptive and lacks a solid empirical base. By contrast, Helm and Schlei(2008) do provide some important empirical insights but their findings focus only on one dimension of WOM namely CRCs.

Given the existing literature and the empirical evidence to date it is possible to identify three broad propositions which conform the basis for a research agenda to examine both the role and management of WOM.

P1: The importance attached to WOM and its effectiveness will be positively related to the presence of experience and credence qualities in the products under consideration.

- P1 follows quite simply from the observation that WOM provides consumers with the opportunity to benefit, pre-purchase, from the experience of others and, thus, reduce the perceived risk associated with purchase. It inconsistent with the argument advanced by Bharadwaj et al. (2003) concerning the importance of WOM-reinforced reputation.

Thus, where managers are aware of the difficulties that consumers experience in relation to product evaluation they will attach much greater significance to WOM in their marketing and will make greater efforts to manage that process (whether by CRCs or by other means).

P2: The more competitive the market, the greater the importance attached to positive WOM as a marketing tool and the greater its effectiveness.

- $\quad$ P2 attempts to link competitive rivalry to the importance of positive WOM. Positive WOM has been identified as having the potential to be highly effective as a form of customer acquisition as well as reinforcing retention(recommenders or advocates are unlikely to defect). When rivalry is high, effective mechanisms for acquisition and retention will be at a premium and given that positive WOM is a form of communication which competitors might find difficult to duplicate, it has the potential to provide a source of competitive advantage. Thus in competitive market environments organisations may be expected to make much greater efforts to manage WOM (either through CRCs or other mechanisms) and will be much more aware of its value and effectiveness.

P3: The more market-oriented the strategy, the greater the importance attached to WOM as part of that strategy.

- P3 simply seeks to explore the extent to which there are relationships between the goals of marketing strategy within an organisation and the extent to which WOM is seen as important and is managed. Satisfaction has been widely identified as a key antecedent to positive WOM and positive WOM has been seen as a facilitator of acquisition and retention. The recognition of the importance of customer satisfaction as an objective of marketing strategy is one key feature of a market led approach to business and those organisations with such an approach would be expected to be much more appreciative of the role of WOM and more aware of its beneficial impact.

These simple propositions suggest a research agenda in which the significance and role of positive WOM communication is influenced by the environment within which the firm operates and the firm's own strategies. The importance of WOM is seen to be dependent on product, market and organisational characteristics and these relationships will be examined in the specific context of financial services where issues of experience and credence are thought to be of particular importance.

\section{Data Collection}

A self-completion questionnaire was thought to be the most cost-effective method of collecting data to evaluate the propositions outlined above and was to be administered by personal delivery. The questionnaire itself was designed to address issues such as product and market characteristics, essential features of marketing strategy, importance of WOM and use of CRCs. Although the current study focused on the financial sector only, this sector covers a considerable range of activities (banking, credit cards, savings, investments, etc.) and this breadth is expected to provide the variation in product market conditions that would be required to gain some insight into the propositions advanced above.

The limited number of studies available that have addressed WOM meant that few standard measurement instruments were available and consequently the majority of scales used were developed based on adaptations from the existing literature and from preliminary discussions with three marketing professionals across different service industries. The questionnaire was piloted with appropriate marketing professionals in India to ensure that the questions proposed were relevant.

Particularly useful literature sources were Haywood (2009) and Helm and Schlei (2008).The former raised 
several critical questions that formed the starting point for a number of questions in the questionnaire, and the latter provided the majority of CRC questions. A five-point Likert scale was adopted for this questionnaire with regards to all attitudinal measures, a standard adopted from other questionnaires investigating WOM (Hansen,1997; Helm and Schlei, 2008; Mittal and Lassar 1998; Spreng et al., 1995). Responses to most scaled items were labelled "strongly agree" and "strongly disagree" at the end points, such that the 'ordinal" quality of the scale allowed for comparisons between responses.

The questionnaire was distributed to financial service sector organisations using a drop-off pick-up approach across a range of locations in northern India. This method was chosen to enhance response rates; given the vagaries of the mail system a conventional postal survey was unlikely to be effective. The questionnaires were distributed between September and December 2010; 250questionnaires were distributed and 73responses obtained, representing a response rate of 29 per cent. Although perhaps a little disappointing, the sample was considered sufficient to justify proceeding with further exploratory analysis.

\section{Data Analysis}

The respondents to the survey were typically operating in both retail and business markets, with 30 per cent indicating that they operated equally in both markets, 23 per cent indicating that they were mainly (but not exclusively) retail and 20 per cent indicating that they were mainly operating in business markets. Delivering a high quality service was identified as the single most important factor contributing to positive WOM (47 percent of respondents); good customer relationships was ranked second (30 per cent) while friendly staff and competitive prices were rated third and fourth respectively.

Table I provides details of the mean scores attached to the different factors contributing to positive WOM and this again confirms the importance of both quality of service and good customer relationships.

\begin{tabular}{lc}
$\begin{array}{l}\text { Table I } \\
\text { Importance of factors stimulating }\end{array}$ \\
\hline \multicolumn{2}{l}{ Mean score } \\
\hline Delivering high quality service \\
Competitive pricing & 4.60 \\
Friendly and helpful staff & 3.86 \\
Good customer relationship & 4.60 \\
Contact with customer service staff & 4.63 \\
Customer referral campaigns & 4.25 \\
Total & 3.86 \\
Note: scale 1-5 & 72.0 \\
\hline
\end{tabular}

Generating positive WOM was identified as an important part of marketing strategies by the majority of respondents and attracted a high rating as shown in Table II. It was rated as a highly effective means of communication and was seen as equally effective in both customer acquisition and retention.

Although CRCs were not rated very highly as factors contributing to the dissemination of positive WOM (along with competitive pricing), the majority of the sample (58 out of 73 ) indicated that they used such campaigns as part of their marketing. The most popular approach was via sales staff (42 per cent of respondents) followed by the provision of literature at point of sale (38 per cent) and targeted mail ( 25 per cent). Only 5 per cent of respondents conducting CRCs made use of the Internet, although given the economic context, this is unsurprising [2].

\begin{tabular}{lc} 
Table II & \\
Role of WOM within marketing strategy & \\
\hline \multicolumn{2}{|c}{ Mean score } \\
\hline $\begin{array}{l}\text { Encouraging woM is key to strategy } \\
\text { What sales staff say is more important }\end{array}$ & 4.13 \\
than what customers say & 2.68 \\
Awareness of service improved & 4.06 \\
through woM & 3.61 \\
$\begin{array}{l}\text { Actively monitor wom } \\
\text { WOM helps to attract customers }\end{array}$ & 4.08 \\
WOM helps with retention & 4.10 \\
WOM is difficult to monitor & 3.26 \\
WOM is one of the most effective forms of & 4.19 \\
communication & 72.0 \\
Total & \\
Note: scale 1-5 &
\end{tabular}

Table III provides information on the relative effectiveness of CRCs in achieving different objectives. Generally, CRCs were rated as being more effective in relation to defensive rather than offensive objectives. 
CRCs were seen as most effective in relation to building close customer relationships (perhaps suggesting that their impact on existing customers may be greater than their impact on new customers) and in relation to targeting. The negative aspects of CRCs such as negative WOM and convincing dissatisfied customers to recommend were not considered particularly significant.

To test the propositions outlined earlier in this paper, the questionnaire collected data on respondents' perceptions of their market environment, the characteristics of the services they offered and the nature of their organisational strategy. Multiple item scales were used to measure these constructs and factor analysis (principal components extraction and vari max rotation) was employed to identify underlying dimensions. Items which cross-loaded or displayed low communalities were excluded resulting in the following set of identified constructs.

\begin{tabular}{lc}
$\begin{array}{l}\text { Table III } \\
\text { Rating of customer referral campaigns }\end{array}$ \\
\hline \multicolumn{2}{|c|}{ Mean score } \\
\hline $\begin{array}{l}\text { Effectiveness for acquisition } \\
\text { Effectiveness in targeting }\end{array}$ & 3.44 \\
Incentives can persuade dissatisfied & 3.88 \\
customers to recommend & 3.68 \\
$\begin{array}{l}\text { CRCs can create negative wom } \\
\text { CRCs reduced need for other forms of }\end{array}$ & 2.64 \\
acquisition & 2.75 \\
Overall, CRCs are successful & 2.49 \\
Total & 3.36 \\
Note: scale 1-5 & 72.0 \\
\hline
\end{tabular}

In the case of the set of measures used to describe the market environment, factor analysis for market characteristics proved ineffective (low value for KMO and Bartlett test suggested that the null hypothesis that the correlation matrix was an identity could not be rejected). Consequently, for testing P1,a single statement about market competitiveness was used, along with an indicator of each organisation's market share (measured on a self-reported scale, relative to the competition). A summary of the extracted factors and their reliability is contained in Table IV. Many of the hypothesised constructs failed to emerge cleanly from the measurement scales and a number of the dimensions which did emerge were characterised by disappointingly low levels of internal reliability. However, given the exploratory nature of the study, it was considered appropriate to proceed with the constructs that emerged in order to obtain some preliminary indications of the impact of context on the role of WOM communication.

With respect to strategic focus, two dimensions appeared to emerge, one of which appeared to suggest an actively customer focused strategy with an emphasis on information gathering and relationship building. By contrast the second construct contained a mix of items which appear to suggest a rather more aggressive or offensive focus and suggested a preference for acquisition over retention. These two measures will serve as the basis for testing P3.

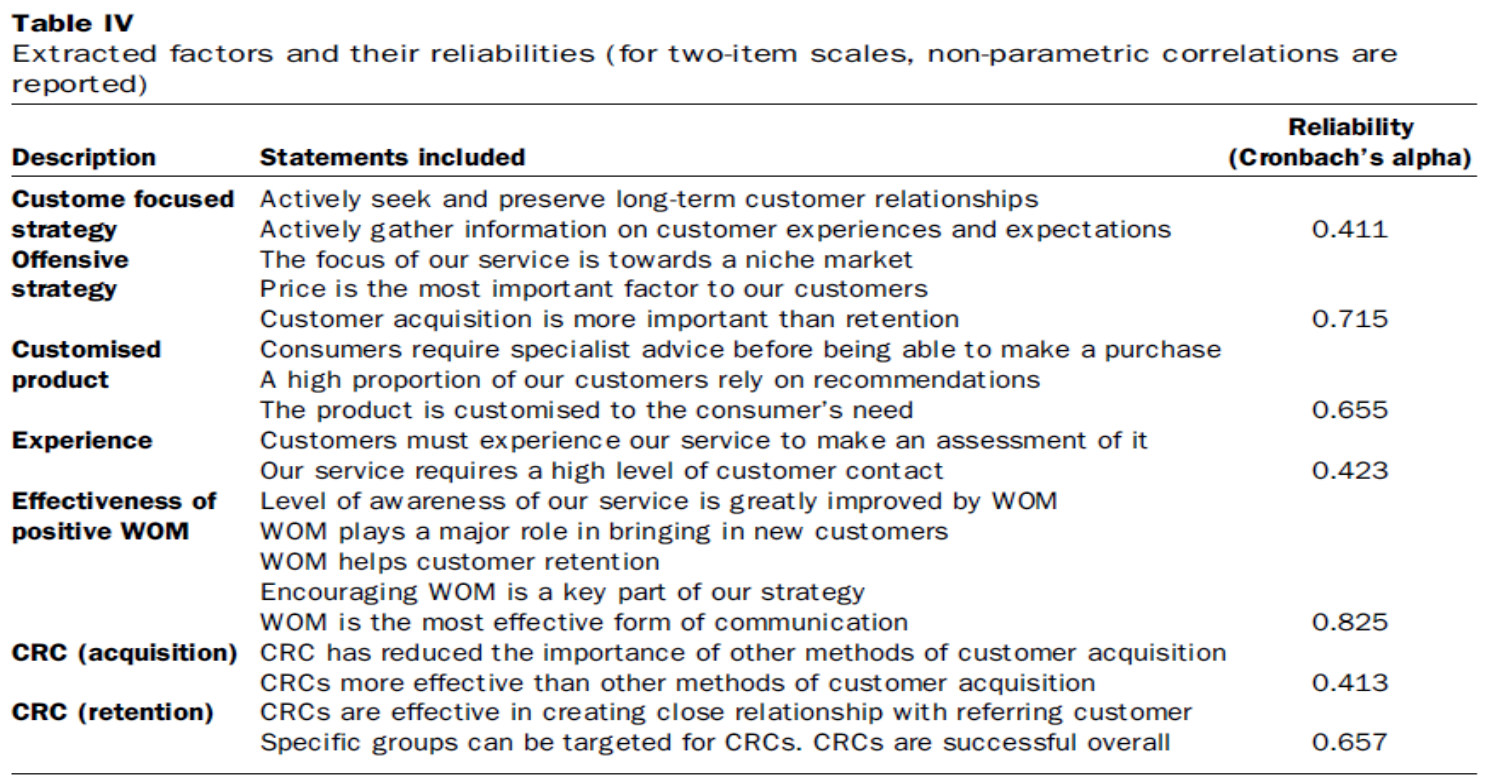

Two dimensions emerged for product characteristics and these will be used to evaluate P1; the first is described as customisation and the implication is that customers require specialist support and advice, pointing to, 
perhaps, the presence of credence qualities in those services. The second dimension is rather more straightforward and measures experience qualities.

Three dependent variables were identified; the first of these (from a factor analysis of a series of statements relating to WOM in general) related to the overall performance of WOM and its general effectiveness. The remaining two measures (from a factor analysis of a series of statements about CRCs in particular) distinguish between the performance of CRCs for retention and for CRCs for acquisition.

Regression analysis was used to attempt tossed light on the propositions advanced earlier in the paper. In each case, the measure of the importance of WOM and two measures of the effectiveness of CRCs were taken as the dependent variables with product, market and strategic variables as predictors. The results are reported in Table $\mathrm{V}$.

Missing values for some variables reduced the sample size to 37 and only two of the estimated models were significant overall. However, the explanatory power for the two models that were significant overall, was respectable and from these, it is possible to obtain some preliminary insights into the research propositions. P1 suggested that product characteristics would affect the importance and effectiveness of WOM. The first equation in Table $\mathrm{V}$ provides no evidence to suggest that product characteristics have any impact on the perceived importance of WOM overall. However, the effectiveness of CRCs for customer retention does appear to be positively related to the degree to which the product is customised (a crude indicator of credence qualities). Product characteristics do not appear to have any impact in relation to the customer acquisition role for CRCs.

\begin{tabular}{|c|c|c|c|}
\hline & Performance of WOM & CRCs for retention & CRCs for acquisition \\
\hline Customise & $\begin{array}{c}0.10 \\
(0.49)\end{array}$ & $\begin{array}{c}0.35 \\
(0.04)\end{array}$ & $\begin{array}{c}0.18 \\
(0.28)\end{array}$ \\
\hline Experience qualities & $\begin{array}{l}-0.25 \\
(0.13)\end{array}$ & $\begin{array}{l}-0.17 \\
(0.36)\end{array}$ & $\begin{array}{c}0.17 \\
(0.37)\end{array}$ \\
\hline Competitiveness & $\begin{array}{c}0.10 \\
(0.49)\end{array}$ & $\begin{array}{c}0.12 \\
(0.47)\end{array}$ & $\begin{array}{c}0.14 \\
(0.41)\end{array}$ \\
\hline Offensive strategy & $\begin{array}{c}0.53 \\
(0.00)\end{array}$ & $\begin{array}{c}0.27 \\
(0.11)\end{array}$ & $\begin{array}{c}0.25 \\
(0.15)\end{array}$ \\
\hline Customer focused strategy & $\begin{array}{c}0.49 \\
(0.00)\end{array}$ & $\begin{array}{c}0.26 \\
(0.14)\end{array}$ & $\begin{array}{l}-0.27 \\
(0.12)\end{array}$ \\
\hline Market share & $\begin{array}{c}0.05 \\
(0.73)\end{array}$ & $\begin{array}{l}-0.01 \\
(0.96)\end{array}$ & $\begin{array}{c}0.03 \\
(0.85)\end{array}$ \\
\hline$R^{2}$ & 0.327 & 0.148 & 0.123 \\
\hline$n$ & 37.0 & 37.0 & 37.0 \\
\hline Significance of $F$ & 0.00 & 0.08 & 0.12 \\
\hline Note: Figures in parenthese & significance levels & & \\
\hline
\end{tabular}

Accordingly, support for P1 is at best, tentative.

There appears to be no evidence to suggest that market environment (competitiveness)has an impact on assessment of the importance and effectiveness of either WOM or CRCs, contrary to the argument put forward for P2.However, as suggested in P3 the nature of the marketing strategy itself does have some impact on the importance of WOM. For the sample as a whole, the dominant strategic focus was offensive with an emphasis on customer acquisition and this facet of strategy did have a large and significant impact on the importance associated with WOM. The more retention-based customer focused strategy was also found to be significant although with a marginally smaller impact. The strategic focus measures were only significant in relation to the importance of WOM overall, although in both of the CRC equations, they were close to being significant, suggesting perhaps a marginal impact. Thus, these results would suggest some preliminary support for P3 and indeed, the balance of evidence from this study would tend to suggest that the importance owe is perhaps more related to an organisations strategic focus than it is to product or market conditions.

\section{Conclusions}

Service marketers have long argued for the importance of positive WOM as a factor influencing consumer selection and usage of services. This form of communication inarguably of particular importance in relation to services which are characterised by a high degree of experience and credence qualities. Financial services provide an example of just such a service. Despite the importance of positive WOM, there has been little research to address this issue from an organisational perspective despite the fact the management of WOM may become an increasingly important marketing activity. This paper seeks to provide some preliminary evidence on the role and management of WOM from an organisational perspective using the case of financial services providers in northern India.

The results of a small scale survey suggest that the active management of WOM via CRCs, although widespread, is less effective than other more relational approaches such as the Delivery of high quality service, 
building good customer relationships and ensuring that staff are friendly and helpful. The literature review suggested that the significance of positive WOM might vary according to product characteristics, the competitive environment and the nature of the organisations approach to marketing. The identification of these constructs empirically proved somewhat problematic, although reasonable approximations were identified. The estimated models suggested that market conditions did not affect the perceived importance of positive WOM (or the effectiveness of CRCs); product characteristics were found to have some tentative impact, but strategic focus was probably the most influential factor, particularly in relation to the perceived importance of WOM. The relatively poor explanatory power of the estimated models would tend to suggest that there are other organisational or market factors that might need to be considered when evaluating the role of WOM and, perhaps more important, that this form of communication is recognised as being effective irrespective of the service, market or organisational context.

Clearly, the small sample size and single sector focus limit the generalise ability of the current findings. Further cross-sect oral work would be desirable to test the impact of context more rigorously as would larger samples. Notwithstanding these limitations, the results do suggest that the importance of positive WOM is widely recognised as are the limitations of CRCs. From a management perspective, the results tend to suggest that actively considering the integration of WOM into marketing strategy may be beneficial and would be consistent with the development of a customer focused approach to a market.

Equally though, it needs to be recognised that generating effective recommendations from consumers may be more reliant on good relationships and good service than on simpleincentives.

\section{References}

[1]. Arndt, J. (1967), “Word of mouth advertising and informal communication", in Cox, D. (Ed.), Risk Taking and Information Handling in Consumer Behaviour, Boston, MA, pp. 188-239.

[2]. Beal, G.M. and Rogers, E.M. (1957), “Informational success in the adoption process of new fabrics", Journal of Home Economics, Vol. XLIX, pp. 630-4.

[3]. Bharadwaj, S.G., Varadarajan, P.R. and Fahy, J.(2003), “'Sustainable competitive advantage in service industries: a conceptual model and research propositions", Journal of Marketing, Vol. 47, October, pp. 83-99.

[4]. Cox, D. (1967), "The audience as communicators", in Cox, D. (Ed.), Risk Taking and Information Handling in Consumer Behaviour, Boston, MA, pp. 172-87.

[5]. Cunningham, S. (1967), "Perceived risk as a factor in informal consumer communications", in Cox, D. (Ed.), Risk Taking and Information Handling in Consumer Behaviour, Boston, MA, pp. 265-88.

[6]. Derbaix, C. (1983), "Perceived risk and risk relievers: an empirical investigation", Journal of Economic Psychology, Vol. 3 No. 2, pp. 19-39.

[7]. Eiglier, P. and Langeard, E. (1977), “A new approach to services marketing", in Eiglier, P., Langeard, E., Lovelock, C., Bateson, J.E.G. and Young, R.F. (Eds), Marketing Consumer Services: New Insights, Marketing Science Institute Report No. 77-115, Marketing Science Institute, Cambridge, MA, pp. 31-58.

[8]. Gabbott, M. and Hogg, G. (2004), “Consumer behaviour and services: a review", Journal of Marketing Management, Vol. 10, pp. $320-4$.

[9]. Gremler, D.D. and Brown, S.W. (1996), “Service loyalty: its nature, importance and limitations", in Edvardsson, B., Brown, S.W., Johnson, R. and Scheuing, E. (Eds), QUIS V Advancing Service Quality: A Global Perspective, ISQA, New York, NY, pp. 171-81.

[10]. Hansen, S. (1997), "Power as a predictor of industrial complaining styles in a buyer/ seller relationship: the buyer's perspective", Journal of Business and Industrial Marketing, Vol. 12 No. 2, pp. 134-48.

[11]. Hart, W.L., Heskett, J.L. and Sasser, W.E. Jr (2007), “The profitable art of service recovery", Harvard Business Review, JulyAugust, pp. 148-56.

[12]. Hartline, M.D. and Jones, K.C. (1996), “Employee performance cues in a hotel environment: influences on perceived service quality, value and word of mouth intentions", Journal of Business Research, Vol. 35, pp. 207-15.

[13]. Haywood, M. (2009), “'Managing word of mouth communications", The Journal of ServicesMarketing, Vol. 3 No. 2 , pp. $55-67$.

[14]. Helm, S. and Schlei, J. (2008), "Referral potential potential referrals. An investigation into customers' communication in service markets", Track 1 Market Relationships, Proceedings 27th EMAC Conference, Marketing Research and Practice, pp. 41-56.

[15]. Holmes, J.H. and Lett, J.D. (1977), “Product sampling and word of mouth", Journal of Advertising, Vol. 17 No. 5, October, pp. 3540 .

[16]. Javalgi R. (1995), "Positioning your service to target key buying influences: the case of referring physicians and hospitals", Journal of Services Marketing, Vol. 9 No. 5, pp. 42-52.

[17]. Katz, E. and Lazarsfeld, P.F. (1955), Personal Influence, The Free Press, Glencoe, IL.

[18]. Mitchell, V. and Greatorex, M. (1993), "Risk perception and reduction in the purchase of consumer services", The Service Industries Journal, Vol. 13 No. 4, pp. 179-200.

[19]. Mittal, B. and Lassar, W. (1998), "Why do customers switch? The dynamics of satisfaction versus loyalty", The Journal of Services Marketing, Vol. 12 No. 3, pp. 177-94.

[20]. Murray, K. (1991), “A test of services marketing theory: consumer information acquisition activities", Journal f Marketing, Vol. 55, pp. 10-25.

[21]. Myers, J.H. and Robertson, T.S. (1972), “Dimensions of opinion leadership", Journal of Marketing Research, Vol. 9, February, pp. 41-6.

[22]. Reichheld, F. and Sasser, W. Jr (1990), "Zero defections: quality comes to services", Harvard Business Review, SeptemberOctober, pp. 105-11.

[23]. Roselius, T. (1971), “Consumer rankings of risk reduction methods", Journal of Marketing, Vol. 35 No. 1, pp. 56-61.

[24]. Selnes, F. (2003), "An examination of the effect of product performance on brand reputation, satisfaction and loyalty", European Journal of Marketing, Vol. 27 No. 9, pp. 19-35.

[25]. Shemwell, D. et al. (1998), “Customer-service provider relationships: an empirical test of a model of service quality, satisfaction and relationship-oriented outcomes", International Journal of Service Industry Management, Vol. 9 No. 2, pp. $155-68$. 
[26]. Singh, J. (1990), “A typology of customer dissatisfaction response styles", Journal of Retailing, Vol. 66 No. 1, pp. 57-97.

[27]. SoËderlund, M. (1998), “Customer satisfaction and its consequences on customer behaviour revisited the impact of different levels of satisfaction on word-of-mouth, feedback to the supplier and loyalty", International Journal of Service Industry Management, Vol. 9 No. 2, pp. $169-88$

[28]. Spreng, R. et al. (1995), “'Service recovery: impact on satisfaction and intentions", Journal of Services Marketing, Vol. 9 No. 1, pp. $15-23$.

[29]. Urbany, J. and Weilbacker, D. (1987), “A critical examination of Nelson's theory of information and consumer behaviour", Journal of Consumer Research, Vol. 16, September, pp. 208-15.

[30]. Walker, J. (2005), “Service encounter satisfaction: conceptualised", Journal of Services Marketing, Vol. 9 No. 1, pp. 5-14.

[31]. Yi, Y. (2009), “A critical review of consumer satisfaction", in Zeithaml, V.A. (Ed.), Review of Marketing, American Marketing Association, Chicago, IL.

[32]. Zeithaml, V. (1981), “How consumer evaluation processes differ between goods and services", in Donnelly, H. and George, W. (Eds), Marketing of Services, American Marketing, Association, Chicago, IL 